\title{
A Centimeter-Sized Quaternary Ti-Zr-Be-Ag Bulk Metallic Glass
}

\author{
S. F. Zhao, Y. Shao, P. Gong, and K. F. Yao \\ School of Materials Science and Engineering, Tsinghua University, Beijing 100084, China \\ Correspondence should be addressed to K. F. Yao; kfyao@tsinghua.edu.cn
}

Received 17 March 2014; Accepted 11 April 2014; Published 28 April 2014

Academic Editor: Na Chen

Copyright (c) 2014 S. F. Zhao et al. This is an open access article distributed under the Creative Commons Attribution License, which permits unrestricted use, distribution, and reproduction in any medium, provided the original work is properly cited.

\begin{abstract}
A novel centimeter-sized Ti-based bulk metallic glass (BMG) was developed by the addition of $\mathrm{Ag}$ in the ternary $\mathrm{Ti}_{41} \mathrm{Zr}_{25} \mathrm{Be}_{34}$ glassy alloy. By replacing Be with Ag, the glass forming ability (GFA), the yield strength, and the supercooled liquid temperature of the quaternary $\mathrm{Ti}_{41} \mathrm{Zr}_{25} \mathrm{Be}_{34-x} \mathrm{Ag}_{x}(x=2,4,6,8$ at.\%) glassy alloys have been obviously enhanced. Among the developed Ti-Zr-Be-Ag alloy systems, the $\mathrm{Ti}_{41} \mathrm{Zr}_{25} \mathrm{Be}_{28} \mathrm{Ag}_{6}$ alloy possesses the largest critical diameter $\left(D_{\max }\right)$ of $10 \mathrm{~mm}$, while the yield strength is also enhanced to $1961 \mathrm{MPa}$, which is much larger than that of $\mathrm{Ti}_{41} \mathrm{Zr}_{25} \mathrm{Be}_{34}(1755 \mathrm{MPa}$ ) alloy. The experimental results show that $\mathrm{Ag}$ is an effective element for improving the GFA and the yield strength of Ti-Zr-Be glassy alloy.
\end{abstract}

\section{Introduction}

Ti-based BMGs have been under intense investigation for many years, owing to their excellent properties, such as low density, high strength, high specific strength, low elastic modulus, and strong corrosion resistance [1-4]. Moreover, the low cost makes the Ti-based BMGs a profound application prospect. Up to date, a number of Ti-based BMGs have been synthesized by the copper mold casting method [57]. However, compared with other alloy systems, the GFA of most Ti-based BMGs is relatively low $[8,9]$. Therefore, it should be of scientific and technological interest to develop Ti-based BMGs with large GFA, together with good mechanical properties. Furthermore, introducing new elements, or so-called "alloying," is proved to be an effective method to improve the GFA of alloys $[8,9]$, which makes the developing of Ti-based BMGs with better GFA and less components more challenging.

It is known that $\mathrm{Ti}_{41} \mathrm{Zr}_{25} \mathrm{Be}_{34}$ ternary BMG possesses a critical size of $5 \mathrm{~mm}$ which is larger than other Ti-Zr-Be ternary alloys $[6,10]$. In the previous work, it shows that its GFA and mechanical properties could be improved through alloying with suitable elements [11, 12]. In this paper, Ag element has been selected as an addition element in the Ti$\mathrm{Zr}$-Be alloy system. By replacing Be with Ag, a series of BMGs with the composition of $\mathrm{Ti}_{41} \mathrm{Zr}_{25} \mathrm{Be}_{34-x} \mathrm{Ag}_{x}(x=2,4,6,8)$, which have improved GFA and mechanical properties, have been obtained.

\section{Experimental Procedure}

The master alloy ingots with nominal compositions of $\mathrm{Ti}_{41} \mathrm{Zr}_{25} \mathrm{Be}_{34-x} \mathrm{Ag}_{x}(x=2,4,6,8$ at.\%) were prepared by arcmelting the mixtures of high-purity $\mathrm{Ti}, \mathrm{Zr}, \mathrm{Be}$, and $\mathrm{Ag}$ metals in a Ti-gettered high-purity $\mathrm{Ar}$ atmosphere. The purity of Be and Ag metals is over $99.99 \%$ in weight, while that of $\mathrm{Ti}$ and $\mathrm{Zr}$ metals is $99.4 \%$ and $99.7 \%$ in weight, respectively. Each ingot was flipped and remelted four times to ensure the homogeneity. Cylindrical rods with different diameters were prepared by copper mold casting method.

The structure of the as-prepared samples was examined by $\mathrm{X}$-ray diffraction $(\mathrm{XRD})$ using $\mathrm{Cu} \mathrm{K} \alpha$ radiation. The thermal stability of the glassy samples was evaluated by differential scanning calorimeter (DSC) at a heating rate of $20 \mathrm{~K} / \mathrm{min}$. Compression tests were carried out on a WDW100 testing machine under a stain rate of $4.2 \times 10^{-4} \mathrm{~s}^{-1}$. The test samples were cut out from the as-cast $\Phi 2 \mathrm{~mm}$ rods with gage aspect ratio of $2: 1$. For the compression tests, at least 3 samples of each glassy alloy were tested. The density $\rho$ of each glassy alloy was measured by Archimedes' principle in the deionized water.

\section{Results}

Figure 1 presents $\mathrm{X}$-ray diffraction spectra of the as-cast $\mathrm{Ti}_{41} \mathrm{Zr}_{25} \mathrm{Be}_{34-x} \mathrm{Ag}_{x}$ BMG samples $(x=2,4,6,8$ at.\%) with the critical diameters. The typical broad halo patterns for 


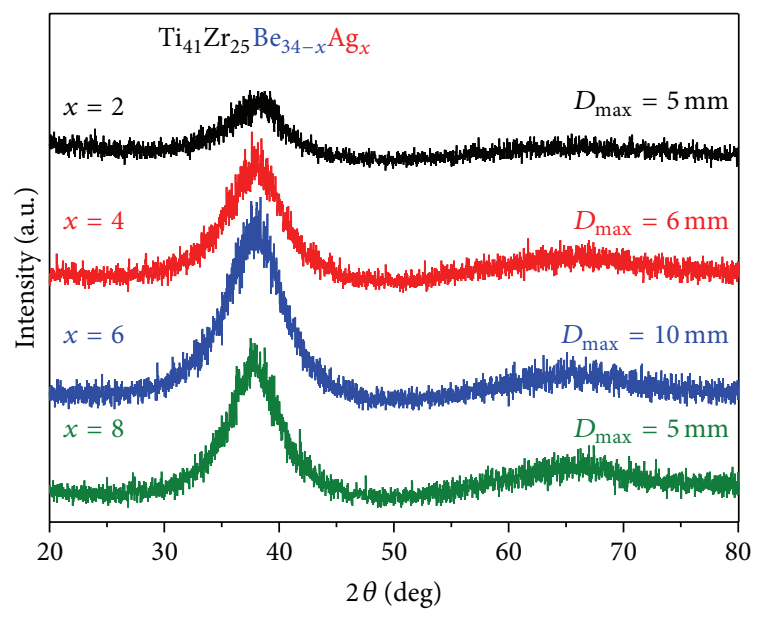

FIGURE 1: XRD patterns for the $\mathrm{Ti}_{41} \mathrm{Zr}_{25} \mathrm{Be}_{34-x} \mathrm{Ag}_{x}(x=2,4,6,8$ at.\%) glassy alloy system with their critical diameters.

the amorphous phases were observed in each XRD spectrum, and no sharp diffraction peaks corresponding to the crystalline phases could be observed. Figure 1 indicates that, with the proper addition of $\mathrm{Ag}$, the GFA of the $\mathrm{Ti}_{41} \mathrm{Zr}_{25} \mathrm{Be}_{34}$ alloy has been obviously improved. Meanwhile, the optimized addition content of $\mathrm{Ag}$ is about 6 at.\%, since its critical diameter for forming fully amorphous structure is $10 \mathrm{~mm}$. As the content of $\mathrm{Ag}$ increased to 8 at.\%, the critical diameter of the $\mathrm{Ti}_{41} \mathrm{Zr}_{25} \mathrm{Be}_{26} \mathrm{Ag}_{8}$ alloy returns to $5 \mathrm{~mm}$, which is the same as that of $\mathrm{Ti}_{41} \mathrm{Zr}_{25} \mathrm{Be}_{34}$ alloy [6]. The experimental results indicate that $\mathrm{Ag}$ is an effective alloying element for improving the GFA of Ti-Zr-Be alloys. In present work, a new centimeter scale quaternary BMG with the nominal composition $\mathrm{Ti}_{41} \mathrm{Zr}_{25} \mathrm{Be}_{28} \mathrm{Ag}_{6}$ has been developed. According to some reported results $[13,14]$, this is the second quaternary centimeter-diameter Ti-based BMG.

Figure 2 shows the DSC curves of the sample cut out from the as-cast fully glassy $\mathrm{Ti}_{41} \mathrm{Zr}_{25} \mathrm{Be}_{34-x} \mathrm{Ag}_{x}(x=2,4,6,8$ at.\%) rods with a diameter of $2 \mathrm{~mm}$. Thermodynamic parameters were measured from the DSC scans, while the glass transition temperature $T_{g}$, initial crystallization temperature $T_{x}$, and liquidus temperature $T_{l}$ were marked with arrows in Figure 2. In addition, for evaluating the GFA of the $\mathrm{Ti}_{41} \mathrm{Zr}_{25} \mathrm{Be}_{34-x} \mathrm{Ag}_{x}$ alloys, the supercooled liquid region $\Delta T_{x}$ (defined as $T_{x}-$ $\left.T_{g}\right), \gamma$ parameter (defined as $T_{x} /\left(T_{g}+T_{l}\right)$ ), and reduced glass transition temperature $T_{\mathrm{rg}}$ (defined as $T_{g} / T_{l}$ ) [15] were calculated as listed in Table 1.

From Figure 2, it can be found that, with the addition of $\mathrm{Ag}, \mathrm{T}_{g}$ decreases from $607 \mathrm{~K}$ for $\mathrm{Ti}_{41} \mathrm{Zr}_{25} \mathrm{Be}_{34}$ [6] alloy to $589 \mathrm{~K}$ for $\mathrm{Ti}_{41} \mathrm{Zr}_{25} \mathrm{Be}_{30} \mathrm{Ag}_{2}$ and $\mathrm{Ti}_{41} \mathrm{Zr}_{25} \mathrm{Be}_{30} \mathrm{Ag}_{4}$ alloy and then slightly increases to $597 \mathrm{~K}$ for $\mathrm{Ti}_{41} \mathrm{Zr}_{25} \mathrm{Be}_{28} \mathrm{Ag}_{6}$ alloy and $593 \mathrm{~K}$ for $\mathrm{Ti}_{41} \mathrm{Zr}_{25} \mathrm{Be}_{26} \mathrm{Ag}_{8}$ alloy, respectively. $T_{x}$ increases from $656 \mathrm{~K}$ for $\mathrm{Ti}_{41} \mathrm{Zr}_{25} \mathrm{Be}_{34}$ [6] alloy to $670 \mathrm{~K}$ for $\mathrm{Ti}_{41} \mathrm{Zr}_{25} \mathrm{Be}_{28} \mathrm{Ag}_{6}$ alloy and then decreases to $654 \mathrm{~K}$ for $\mathrm{Ti}_{41} \mathrm{Zr}_{25} \mathrm{Be}_{26} \mathrm{Ag}_{8}$ alloy. It should be noted that, with Ag addition, the value of $\Delta T_{x}$ has been obviously enlarged; especially, $\mathrm{Ti}_{41} \mathrm{Zr}_{25} \mathrm{Be}_{30} \mathrm{Ag}_{4}$ glass alloy has the largest supercooled liquid region of $81 \mathrm{~K}$ in the Ti-Zr-Be-Ag alloy system. $\Delta T_{x}$

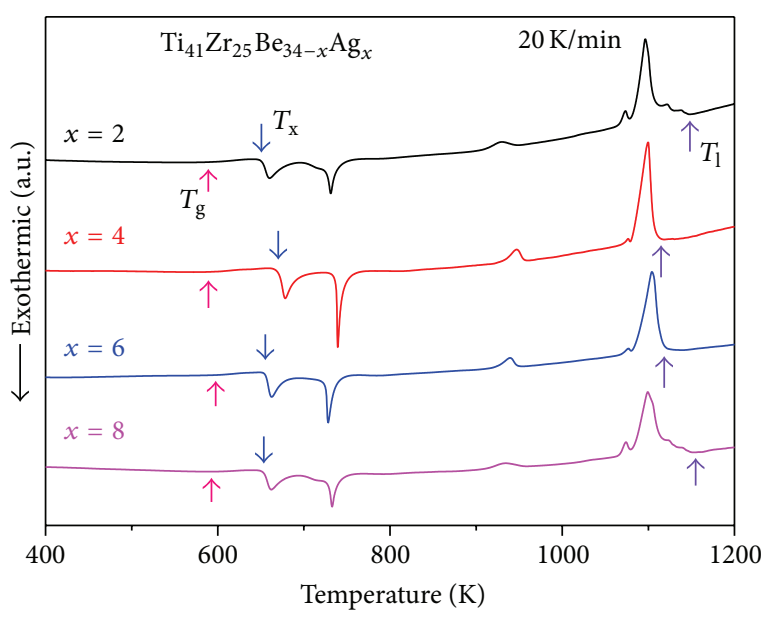

FIGURE 2: DSC curves of the $\mathrm{Ti}_{41} \mathrm{Zr}_{25} \mathrm{Be}_{34-x} \mathrm{Ag}_{x}(x=2,4,6,8$ at.\%) glassy alloys.

is considered as a measure to evaluate the thermal stability related to supercooled liquid stability against crystallization [16]; thus Ag addition can effectively improve the thermal stability of the Ti-Zr-Be-Ag glassy alloy. Moreover, the variation tendency of $T_{\mathrm{rg}}$ and $\gamma$ with the Ag content in the alloy is roughly the same. The value of $T_{\text {rg }}$ for $\mathrm{Ti}_{41} \mathrm{Zr}_{25} \mathrm{Be}_{28} \mathrm{Ag}_{6}$ alloy is the largest among all the Ti-Zr-Be-Ag alloys, and $\mathrm{Ti}_{41} \mathrm{Zr}_{25} \mathrm{Be}_{30} \mathrm{Ag}_{4}$ alloy possesses the largest $\gamma$ value and the lowest $T_{l}$ value. It is suggested that these two alloys may possess relatively good GFA [16], which is in accordance with the experimental results.

Figure 3 shows the compressive stress-strain curves of $\mathrm{Ti}_{41} \mathrm{Zr}_{25} \mathrm{Be}_{34-x} \mathrm{Ag}_{x}(x=2,4,6,8$ at. \%) at room temperature. The yield strength $\sigma_{0.2}$, the maximum compression stress $\sigma_{\text {max }}$, and the plastic strain $\varepsilon_{p}$ of the $\mathrm{Ti}_{41} \mathrm{Zr}_{25} \mathrm{Be}_{34-x} \mathrm{Ag}_{x}$ BMGs were listed in Table 2 . In the present work, the addition of Ag enhances the density of Ti-Zr-Be alloy, while the value of the specific strength (defined as yield strength/density) of $\mathrm{Ti}_{41} \mathrm{Zr}_{25} \mathrm{Be}_{34-x} \mathrm{Ag}(x=2,4,5,6,8)$ BMGs does not change a lot. According to the reported results, the Ag-free alloy exhibits a yield strength $\sigma_{0.2}$ of $1755 \mathrm{MPa}$, a maximum compressive strength $\sigma_{\max }$ of $1914 \mathrm{MPa}$, and a plastic strain $\varepsilon_{p}$ of $2.9 \%$ [6]. As shown in Figure 3, Ag addition can greatly increase the yield strength of the BMGs.

For the glassy alloy with optimum Ag content of 6 at.\%, the yield strength $\sigma_{0.2}$ is $1964 \mathrm{MPa}$, while with 8 at.\% of $\mathrm{Ag}$, the maximum compression stress $\sigma_{\max }$ and plastic strain $\varepsilon_{p}$ are $2054 \mathrm{MPa}$ and $4.8 \%$, respectively. The present results indicate that Ag addition could effectively improve the mechanical properties of Ti-Zr-Be glassy alloys.

It shows that, among the quaternary $\mathrm{Ti}-\mathrm{Zr}-\mathrm{Be}-\mathrm{Ag}$ alloy system, $\mathrm{Ti}_{41} \mathrm{Zr}_{25} \mathrm{Be}_{28} \mathrm{Ag}_{6}$ glassy alloy possesses not only the largest GFA, but also high strength and good compressive plastic strain.

\section{Discussion}

It is known that the mixing enthalpies $\Delta H_{\text {mix }}$ between $\mathrm{Ti}$ Ag, Ti-Zr, Zr-Ag, Ti-Be, Ag-Be, and Zr-Be are $-2 \mathrm{~kJ} / \mathrm{mol}$, 
TABLE 1: Thermal parameters of $\mathrm{Ti}_{41} \mathrm{Zr}_{25} \mathrm{Be}_{34-x} \mathrm{Ag}_{x}(x=2,4,6,8$ at.\%) BMGs. The error of the temperature values is $\pm 1 \mathrm{~K}$.

\begin{tabular}{lccccccc}
\hline Composition (at.\%) & $T_{g}(\mathrm{~K})$ & $T_{x}(\mathrm{~K})$ & $\Delta T_{x}(\mathrm{~K})$ & $T_{l}(\mathrm{~K})$ & $T_{\mathrm{rg}}=T_{g} / T_{l}$ & $\gamma$ & $D_{\max }(\mathrm{mm})$ \\
\hline $\mathrm{Ti}_{41} \mathrm{Zr}_{25} \mathrm{Be}_{34}[6]$ & 607 & 656 & 49 & 1123 & 0.5405 & 0.3792 & $\Phi 5$ \\
$\mathrm{Ti}_{41} \mathrm{Zr}_{25} \mathrm{Be}_{32} \mathrm{Ag}_{2}$ & 589 & 651 & 62 & 1148 & 0.5131 & 0.3748 & $\Phi 5$ \\
$\mathrm{Ti}_{41} \mathrm{Zr}_{25} \mathrm{Be}_{30} \mathrm{Ag}_{4}$ & 589 & 670 & 81 & 1107 & 0.5321 & 0.3950 & $\Phi 6$ \\
$\mathrm{Ti}_{41} \mathrm{Zr}_{25} \mathrm{Be}_{28} \mathrm{Ag}_{6}$ & 597 & 655 & 58 & 1118 & 0.5340 & 0.3819 & $\Phi 10$ \\
$\mathrm{Ti}_{41} \mathrm{Zr}_{25} \mathrm{Be}_{26} \mathrm{Ag}_{8}$ & 593 & 654 & 61 & 1153 & 0.5143 & 0.3746 \\
\hline
\end{tabular}

TABLE 2: Densities and mechanical properties of $\mathrm{Ti}_{41} \mathrm{Zr}_{25} \mathrm{Be}_{34-x} \mathrm{Ag}_{x}(x=2,4,6,8$ at.\%) BMGs.

\begin{tabular}{lccccc}
\hline Composition (at.\%) & Density $\left(\mathrm{g} / \mathrm{cm}^{3}\right)$ & $\sigma_{0.2}(\mathrm{MPa})$ & $\sigma_{\max }(\mathrm{MPa})$ & $\varepsilon_{p}(\%)$ & Specfic strength $(\mathrm{Nm} / \mathrm{Kg})$ \\
\hline $\mathrm{Ti}_{41} \mathrm{Zr}_{25} \mathrm{Be}_{34}[6]$ & 4.76 & 1755 & 1914 & $2.9 \pm 0.1$ & $3.69 \times 10^{5}$ \\
$\mathrm{Ti}_{41} \mathrm{Zr}_{25} \mathrm{Be}_{32} \mathrm{Ag}_{2}$ & 5.01 & 1808 & 1882 & $2.4 \pm 0.1$ & $3.61 \times 10^{5}$ \\
$\mathrm{Ti}_{41} \mathrm{Zr}_{25} \mathrm{Be}_{30} \mathrm{Ag}_{4}$ & 5.13 & 1931 & 1995 & $2.9 \pm 0.1$ & $3.76 \times 10^{5}$ \\
$\mathrm{Ti}_{41} \mathrm{Zr}_{25} \mathrm{Be}_{28} \mathrm{Ag}_{6}$ & 5.27 & 1961 & 2013 & $2.3 \pm 0.1$ & $3.73 \times 10^{5}$ \\
$\mathrm{Ti}_{41} \mathrm{Zr}_{25} \mathrm{Be}_{26} \mathrm{Ag}_{8}$ & 5.42 & 1946 & 2054 & $4.8 \pm 0.1$ & $3.59 \times 10^{5}$ \\
\hline
\end{tabular}

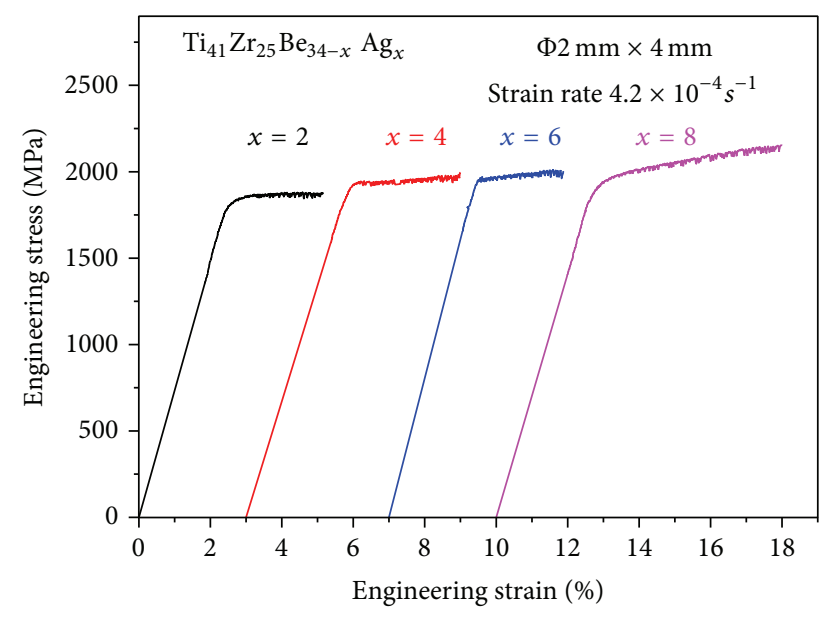

Figure 3: Compressive stress-strain curves at room temperature for $\mathrm{Ti}_{41} \mathrm{Zr}_{25} \mathrm{Be}_{34-x} \mathrm{Ag}_{x}(x=2,4,6,8$ at.\%) glassy samples.

$0 \mathrm{~kJ} / \mathrm{mol},-20 \mathrm{~kJ} / \mathrm{mol},-30 \mathrm{~kJ} / \mathrm{mol}, 2 \mathrm{~kJ} / \mathrm{mol}$, and $-43 \mathrm{~kJ} / \mathrm{mol}$, respectively [17]. Thus, in the Ti-Zr-Be-Ag alloy system, the strong chemical short-range order clusters or medium-range order clusters would be expected [18], which may restrain the diffusion of the atoms, and could suppress crystallization during the solidification. Meanwhile, the addition of $\mathrm{Ag}$ increases the number of the components in the alloy, which could generate more types of local ordering clusters and stabilize the liquid phase [18].

In addition, the electronegativity difference $\Delta x$ and the atomic size difference parameter $\delta$, the two parameters that related to the GFA of the glassy alloy, have been applied to evaluate the effect of $\mathrm{Ag}$ addition on the GFA of Ti-Zr-Be glassy alloy [19]. $\delta$ is defined as $\delta=\sqrt{\sum_{i=1}^{n} c_{i}\left(1-r_{i} / \bar{r}\right)}, \Delta x$ is defined as $\Delta x=\sqrt{\sum_{i=1}^{n} c_{i} \times\left(x_{i}-\bar{x}\right)^{2}}$, where $\bar{r}=\sum_{i=1}^{N} c_{i} r_{i}, \bar{x}=$ $\sum_{i=1}^{N} c_{i} x_{i}, c_{i}$ is the atomic fraction, $r_{i}$ and $x_{i}$ are atomic radius and electronegativity of $i$ th element, and $N$ is the number of allying elements $[20,21] . \Delta x$ and $\delta$ of Ti-Zr-Be-Ag glassy alloys were calculated and summarized in Figure 4.

According to the Hume-Rothery rules and Inoue's three empirical rules $[20,21]$, the alloys with larger value of $\delta$ and $\Delta x$ could form amorphous phase readily. As shown in Figure 4, because Ag possesses larger Pauling electronegativity (1.91) than $\mathrm{Ti}$ (1.54), $\mathrm{Zr}$ (1.33), and $\mathrm{Be}$ (1.57), the addition of $\mathrm{Ag}$ would increase the value of $\Delta x$ in the Ti-Zr-Be alloys, which effectively enhance the GFA. However, the value of $\delta$ would decrease as the content of $\mathrm{Ag}$ increase, which is not beneficial to improve the GFA [22]. When the content of Ag is relatively low, the beneficial effect of $\Delta x$ dominates the alloying effect on GFA. So the critical size increases with $\mathrm{Ag}$ content and reached the maximum value of $10 \mathrm{~mm}$ at 6 at.\%. When increasing $\mathrm{Ag}$ content again, the effect from $\delta$ would significantly reduce the beneficial effect from $\Delta x$, resulting in the decrease of GFA. Similar effects have also been observed in Ti-Zr-Be-Al [8] and Ti-Zr-Be-Fe [6] quaternary BMGs, too. Due to the efforts of these two factors, there would exist an optimized $\mathrm{Ag}$ content in the $\mathrm{Ti}-\mathrm{Zr}$-Be alloy system, which is 6 at.\%.

\section{Conclusion}

In summary, Ag addition could significantly improve the GFA, thermal stability, and mechanical properties of the TiZr-Be glassy alloys. By replacing Be with Ag, it has been found that the developed $\mathrm{Ti}_{41} \mathrm{Zr}_{25} \mathrm{Be}_{28} \mathrm{Ag}_{6}$ alloy possesses much better GFA; the critical diameter of the quaternary BMG has been increased to $10 \mathrm{~mm}$, while that of ternary $\mathrm{Ti}_{41} \mathrm{Zr}_{25} \mathrm{Be}_{34}$ [6] alloy is only $5 \mathrm{~mm}$. This alloy also exhibits a yield strength of $1961 \mathrm{MPa}, 10 \%$ higher than that of $\mathrm{Ti}_{41} \mathrm{Zr}_{25} \mathrm{Be}_{34} \mathrm{BMG}$ [6]. Furthermore, The Ti-Zr-Be-Ag glassy alloys have a wider supercooled liquid temperature range than that of the $\mathrm{Ti}_{41} \mathrm{Zr}_{25} \mathrm{Be}_{34}$ glassy alloys, indicating a higher thermal stability of the glassy alloys. The enhanced GFA is supposed to be related to the improved atomic packing efficiency and high electronegativity difference, which can retard the atomic diffusion due to the addition of $\mathrm{Ag}$. 


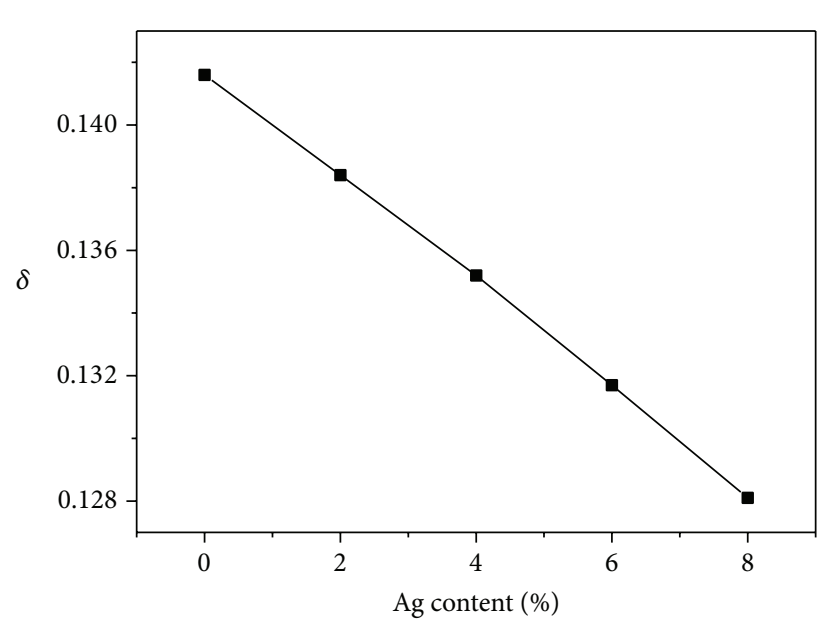

(a)

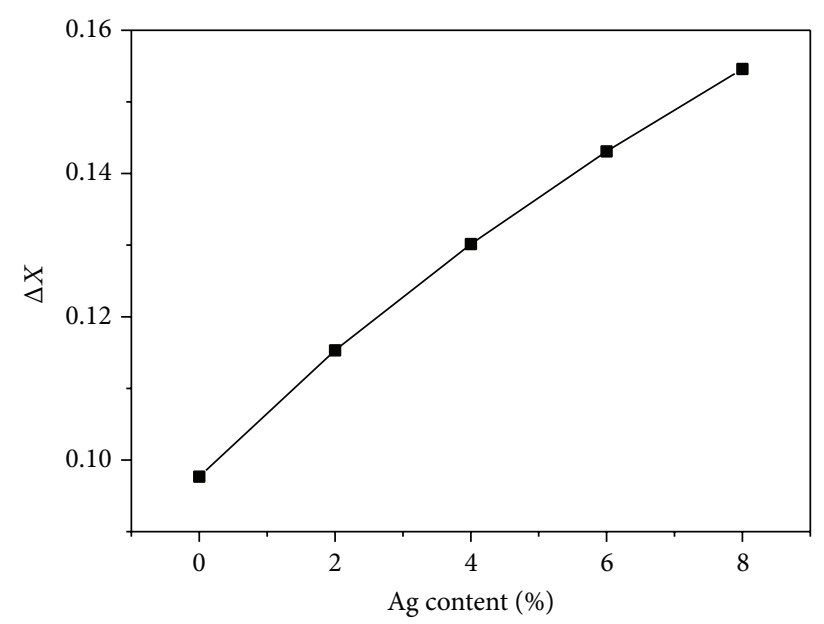

(b)

FIGURE 4: The atomic size parameter $\delta$ (a) and the electronegativity difference $\Delta x$ (b) of $\operatorname{Ti}_{41} \mathrm{Zr}_{25} \mathrm{Be}_{34-x} \mathrm{Ag}_{x}(x=2,4,6,8$ at.\%) glassy alloys.

\section{Conflict of Interests}

The authors declare that there is no conflict of interests regarding the publication of this paper.

\section{References}

[1] A. L. Greer, “Confusion by design," Nature, vol. 366, no. 6453, pp. 303-304, 1993.

[2] K. F. Yao, F. Ruan, Y. Q. Yang, and N. Chen, "Superductile bulk metallic glass," Applied Physics Letters, vol. 88, no. 12, Article ID 122106, 2006.

[3] K. F. Xie, K. F. Yao, and T. Y. Huang, "Preparation of (Ti0.45Cu0.378Zr0.10Ni 0.072)100-xSnx bulk metallic glasses," Journal of Alloys and Compounds, vol. 504, no. 1, pp. S22-S26, 2010.

[4] D. E. Polk, A. Calka, and B. C. Giessen, "The preparation and thermal and mechanical properties of new titanium rich metallic glasses," Acta Metallurgica, vol. 26, no. 7, pp. 1097-1103, 1978.

[5] Y. C. Kim, W. T. Kim, and D. H. Kim, "A development of Tibased bulk metallic glass," Materials Science and Engineering A, vol. 375-377, no. 1-2, pp. 127-135, 2004.

[6] P. Gong, K. Yao, and Y. Shao, "Effects of Fe addition on glassforming ability and mechanical properties of Ti-Zr-Be bulk metallic glass," Journal of Alloys and Compounds, vol. 536, pp. 26-29, 2012.

[7] P. Gong, K. F. Yao, X. Wang, and Y. Shao, "Centimeter-sized Tibased bulk metallic glass with high specific strength," Progress in Natural Science: Materials International, vol. 22, pp. 401-406, 2012.

[8] P. Gong, K. Yao, and Y. Shao, "Lightweight Ti-Zr-Be-Al bulk metallic glasses with improved glass-forming ability and compressive plasticity," Journal of Non-Crystalline Solids, vol. 358, pp. 2620-2625, 2012.

[9] M. F. Ashby and A. L. Greer, "Metallic glasses as structural materials," Scripta Materialia, vol. 54, no. 3, pp. 321-326, 2006.

[10] Y. Zhang, W. G. Zhang, J. P. Lin, G. J. Hao, G. L. Chen, and P. K. Liaw, "Glass-forming ability and competitive crystalline phases for lightweight Ti-Be-based alloys," Metallurgical and Materials Transactions A, vol. 41, no. 7, pp. 1670-1676, 2010.

[11] Y. Zhang, J. Chen, G. L. Chen, and X. J. Liu, "Glass formation mechanism of minor yttrium addition in CuZrAl alloys," Applied Physics Letters, vol. 89, no. 13, Article ID 131904, 2006.

[12] Z. B. Jiao, H. X. Li, J. E. Gao, Y. Wu, and Z. P. Lu, "Effects of alloying elements on glass formation, mechanical and softmagnetic properties of Fe-based metallic glasses," Intermetallics, vol. 19, no. 10, pp. 1502-1508, 2011.

[13] P. Gong, K. Yao, and H. Ding, "Centimeter-sized Ti-based quaternary bulk metallic glass prepared by water Quenching," International Journal of Modern Physics B, vol. 27, no. 18, 2013.

[14] P. Gong, K. Yao, X. Wang, and Y. A. Shao, "A new centimetersized Ti-based quaternary bulk metallic glass with good mechanical properties," Advanced Engineering Materials, vol. 15, pp. 691-696, 2013.

[15] Z. P. Lu and C. T. Liu, "A new glass-forming ability criterion for bulk metallic glasses," Acta Materialia, vol. 50, no. 13, pp. 35013512, 2002.

[16] Z. P. Lu, Y. Li, and S. C. Ng, "Reduced glass transition temperature and glass forming ability of bulk glass forming alloys," Journal of Non-Crystalline Solids, vol. 270, no. 1-3, pp. 103-114, 2000.

[17] A. Takeuchi and A. Inoue, "Classification of bulk metallic glasses by atomic size difference, heat of mixing and period of constituent elements and its application to characterization of the main alloying element," Materials Transactions, vol. 46, no. 12, pp. 2817-2829, 2005.

[18] G. Chen, X. Hui, S. Fan, H. Kou, and K. Yao, "Concept of chemical short range order domain and the glass forming ability in multicomponent liquid," Intermetallics, vol. 10, no. 11-12, pp. 1221-1232, 2002.

[19] O. N. Senkov and D. B. Miracle, "Effect of the atomic size distribution on glass forming ability of amorphous metallic alloys," Materials Research Bulletin, vol. 36, no. 12, pp. 2183-2198, 2001.

[20] A. Takeuchi and A. Inoue, "Quantitative evaluation of critical cooling rate for metallic glasses," Materials Science and Engineering $A$, vol. 304-306, no. 1-2, pp. 446-451, 2001. 
[21] S. Fang, X. Xiao, L. Xia, W. Li, and Y. Dong, "Relationship between the widths of supercooled liquid regions and bond parameters of Mg-based bulk metallic glasses," Journal of NonCrystalline Solids, vol. 321, no. 1-2, pp. 120-125, 2003.

[22] A. Inoue and A. Takeuchi, "Recent development and application products of bulk glassy alloys," Acta Materialia, vol. 59, no. 6, pp. 2243-2267, 2011. 

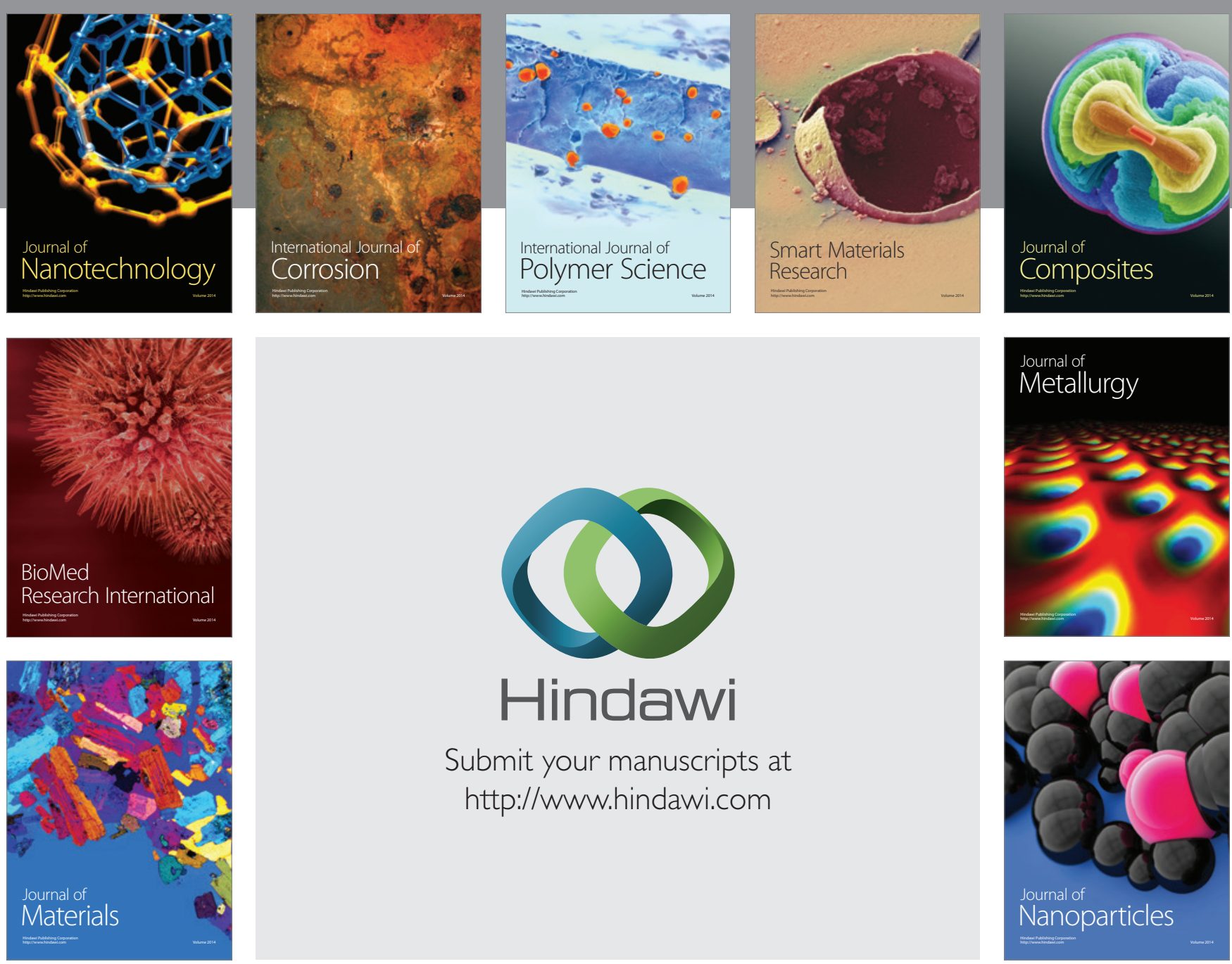

Submit your manuscripts at http://www.hindawi.com
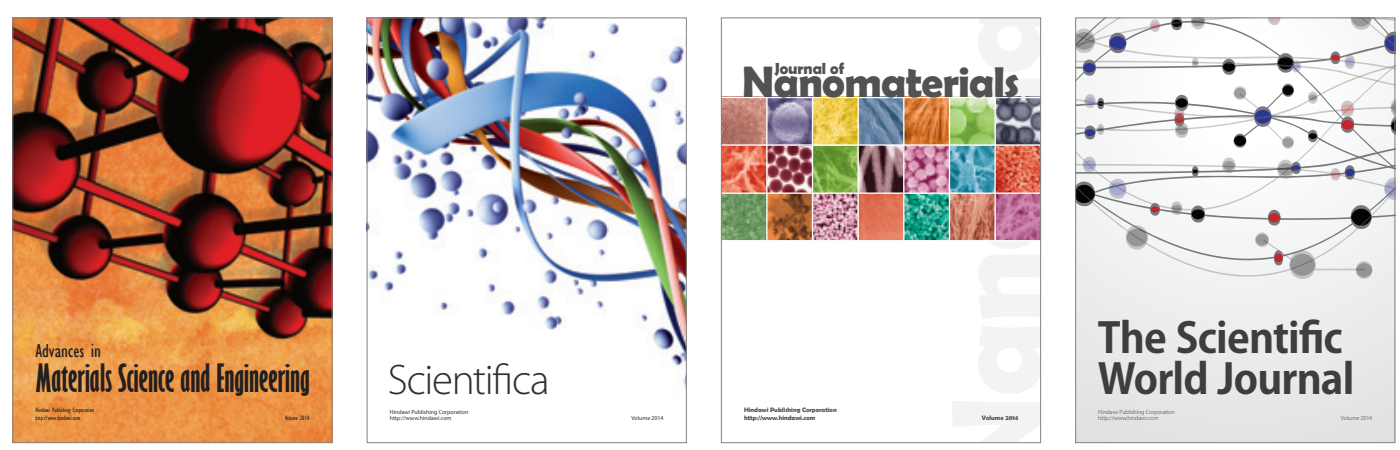

\section{The Scientific World Journal}
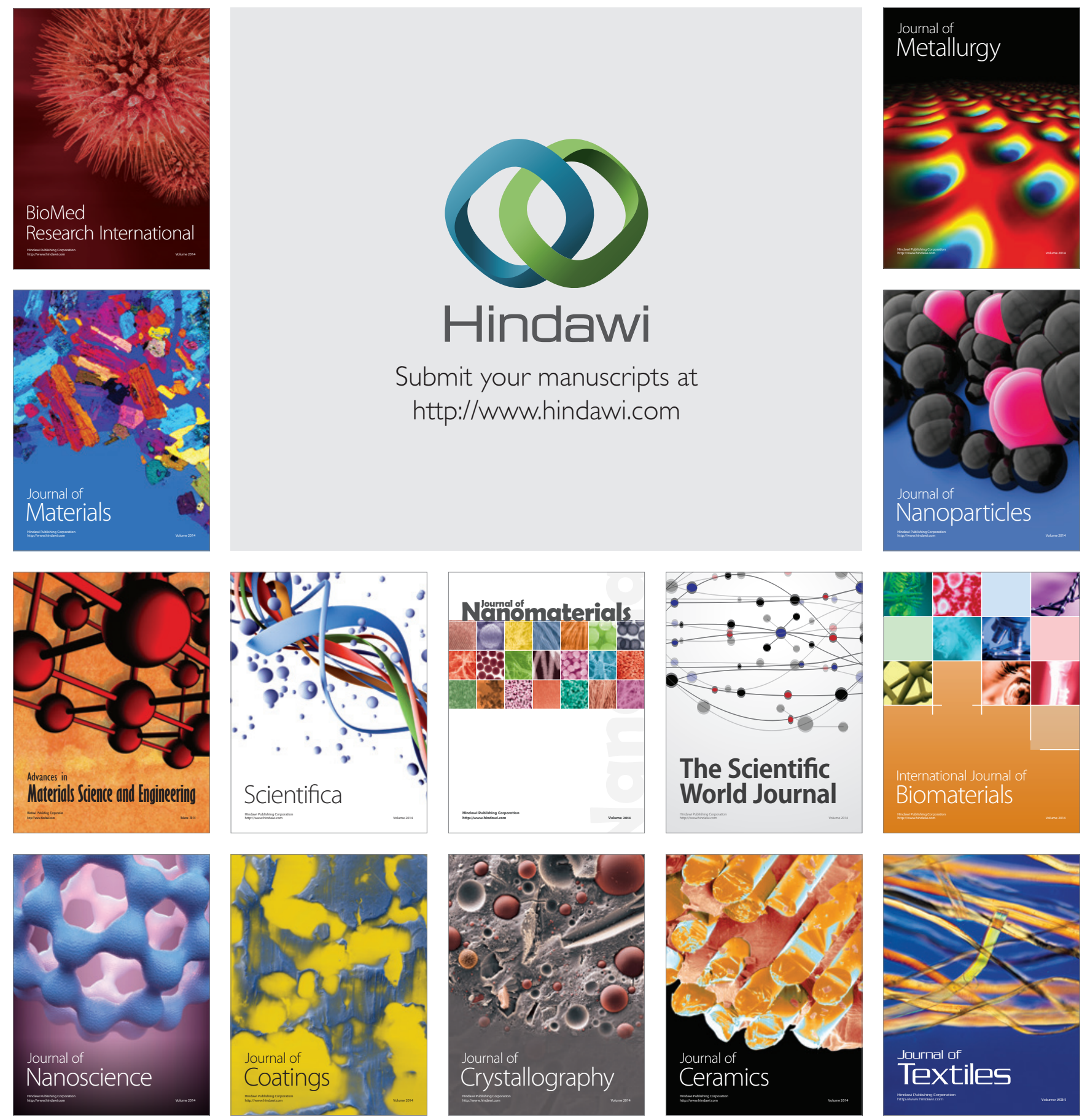